Retraction

\title{
Retraction: Paul, S.C. et al. Properties of Normal and Recycled Brick Aggregates for Production of Medium Range (25-30 MPa) Structural Strength Concrete. Buildings 2018, 8, 72
}

\author{
Suvash Chandra Paul ${ }^{1, *(\mathbb{D})}$, Adewumi John Babafemi ${ }^{2}$, Vivi Anggraini ${ }^{1}$ \\ and Md. Minhaz Rahman ${ }^{3}$ \\ 1 Department of Civil Engineering, School of Engineering, Monash University Malaysia, Bandar Sunway, \\ 47500 Subang Jaya, Malaysia; vivi.anggraini@monash.edu \\ 2 Department of Building, Faculty of Environmental Design and Management, Obafemi Awolowo University, \\ Ile-Ife 220282, Nigeria; ajbabafemi@oauife.edu.ng \\ 3 Structural Engineers Limited (SEL), West Panthapath, Dhaka 1209, Bangladesh; zishan179@yahoo.com \\ * Correspondence: suvash.chandra@monash.edu
}

Received: 4 June 2018; Accepted: 11 June 2018; Published: 11 June 2018

As the authors of the title paper [1], it is with great regret that we inform the readership of Buildings that we have asked the journal's publisher, MDPI, to retract the paper from the scientific literature. The reason for this action is that this paper was part of a final year research project carried out by Suvash Chandra Paul and Md. Minhaz Rahman and supervised by Tarek Uddin Mohammed. Unfortunately, we did not include Tarek Uddin Mohammed as an author and he did not agree to its publication. We wish to apologise to the Buildings journal editors, MDPI, and of course to the wider scientific community for any inconvenience this action may have caused.

\section{Reference}

1. Paul, S.C.; Babafemi, A.J.; Anggraini, V.; Rahman, M.M. Properties of normal and recycled brick aggregates for production of medium range (25-30 MPa) structural strength concrete. Buildings 2018, 8, 72. [CrossRef]

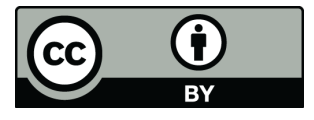

(C) 2018 by the authors. Licensee MDPI, Basel, Switzerland. This article is an open access article distributed under the terms and conditions of the Creative Commons Attribution (CC BY) license (http:/ / creativecommons.org/licenses/by/4.0/). 